\title{
Questionnaire Development for Strategic English Learning: Processes and Outcomes
}

\author{
Dr. Hoang Nguyen (Corresponding author) \\ Faculty of Education, University of Tasmania, Launceston, Australia \\ Locked Bag 1307, Launceston, Tasmania, Australia 7250 \\ E-mail: hoang.nguyen@utas.edu.au
}

\begin{abstract}
Dr. Daniel R Terry
Department of Rural Health, University of Melbourne, Shepparton, Australia

PO Box 6500 Shepparton, Victoria, Australia 3632

E-mail: d.terry@unimelb.edu.au
\end{abstract}

\begin{abstract}
Dr. Si Fan
Faculty of Education, University of Tasmania, Launceston, Australia

Locked Bag 1307, Launceston Tasmania 7250

E-mail: Si.Fan@utas.edu.au
\end{abstract}

Received: January 18, 2016 Accepted: February 3, 2016 Published: February 3, 2016

doi:10.5296/ijele.v4i1.8970 URL: http://dx.doi.org/10.5296/ijele.v4i1.8970

\begin{abstract}
This paper reports on the four-stage construction of the English Language Learning Strategy Questionnaire (ELLSQ), employed in a research study on language learning strategies (LLSs) among Vietnamese tertiary students. Firstly, a needs analysis for the questionnaire development is provided. Secondly, various steps in the adaptation and initial development of the ELLSQ are described in detail, including the review of relevant literature, consultation with survey experts, and focus group discussions with target learners. Thirdly, the refinement of the ELLSQ is addressed through the conduction of informal expert reviews; and finally, its validation through field pre-tests is reported. The reliability and validity of the ELLSQ was undertaken through a pilot test with participation of 97 students, who were part of the target
\end{abstract}


population of the formal study. The main purpose of this pilot test was to ensure the workability of the instrument and to establish reliability, face and content validity of the questionnaire. Practical implications for future attempts are embedded regarding the construction of reliable and valid questionnaires in a new research discourse.

Keywords: Learning strategies; Second Language Learning; English; Vietnamese; tertiary students; questionnaire development.

\section{Introduction}

Language learning strategies (LLSs) have been widely documented to play an important role in language development. According to Rubin and Wenden (1987, p. 23), LLSs "contribute to the development of language system which the learner constructs and affect learning directly". On a clearer note, Bialystok (1978, p. 71) stated strategies were "optimal means for exploiting available information to improve competence in a second language". With the addition of the affective element, Oxford (1990) defines strategies as belhaviours or actions that learners use to make language learning more successful, self-directed and enjoyable. Other researchers such as MacIntyre (1994) and Cohen (1998) place an emphasis on learners' deliberateness in the employment of language learning strategies. In Cohen's (1998, p. 4) definition, for example, strategies are those "consciously selected by learners and which may result in action taken to enhance the learning or use of a second or foreign language, through the storage, retention, recall, and application of information about the language". Varied as they are in lexical choices, these statements agree upon central role of LLSs in facilitating and accelerating the language learning process.

Although it has been over 35 years since the first research effort in LLSs was carried out, "language learning strategy research is still quite an immature field" (Gremfell \& Erler, 2007, p. 28). One possible explanation for this is the extensive scope of the LLS area, which involves not only the learner's learning process, but also its correlation with teaching and other learner/learning variables (Grenfell \& Erler, 2007). With this aspiration, researchers in the field encounter considerable challenges, among which the development of reliable and valid research tools has been an issue.

A comprehensive review of literature has revealed there is a need for updated tools to measure the range and patterns of LLS use by language learners. Firstly, in this age of technologically assisted language learning, new teaching and learning modes are constantly created, prompting learners to adopt new learning approaches and strategies. Teaching and learning are no longer bound by time and place as learning resources are much more accessible thanks to the Internet. In addition, there is a propensity for teaching staff to be more approachable. In this learning context, the modern language learner constantly experiments with new strategies in the new learning environment and these strategies need to be reflected in LLS measurements.

Secondly, there has been substantial consensus about the dynamic nature of LLSs. Specifically, LLSs are said to be culturally-situated, contextually-bound, and learner-specific. 
In other words, the development of learner strategies is closely linked to the type of learning, cultural and social context in which they are positioned. For instance, Usuki (2000) suggests active learning is instilled within learners in one culture whereas a passive approach is traditionally encouraged in another. The dynamicity of LLSs is also manifest in its connection with learner variables, such as motivation, attitude, age, and gender. These learner variables are said to play a role in determining the appropriateness and effectiveness of certain LLSs to various extents (Peacork \& Ho, 2003; Wharton, 2000; Xu, 2011)

All of these premises about LLSs have made it extremely challenging to devise a universally applicable questionnaire, which can be flexible enough to capture all of the variations in LLSs across different education discourses (Locastro, 1994; Gao, 2004). Even the Strategy Inventory for Language Learning (SILL) developed by Oxford (1986; 1990), a highly reliable and widely used tool across cultural groups of learners (Chamot, 2004; Magno, 2010; Su \& Duo, 2012; Yin, 2008; Zare, 2010), has been questioned about its validity and reliability (e.g. Oxford \& Ehrman, 1995). Other attempts were made to develop survey questionnaires to suit specific learning and teaching situations (Cohen \& Chi, 2002; Griffiths, 2003; Prakongchati, 2007; Purpura, 1999; Wen, 1995). A questionnaire on self-directed language learning attitudes and strategies, developed by Gan (2004 ), is one example. However, there is inadequate methodological research reported on the validation of these questionnaires and hence limited interest in their re-examination and further improvement. Given the infancy stage of LLS research in Vietnam, there has been a paucity of reliable questionnaires to measure the LLSs among Vietnamese learners.

In this research, an attempt was made to construct the ELLSQ, which is more reflective of and relevant to the context of English teaching and learning in Vietnamese tertiary education. Partly adapted from current established tools, the ELLSQ underwent various stages of development, refinement and validation to achieve its reliability and validity in the targeted education discourse.

\section{The Four-stage Construction}

In this study, the ELLSQ was designed to create a valid context-sensitive and learner-appropriate questionnaire of LLS among Vietnamese EFL tertiary students. The design used a four-stage approach and for each stage key objectives were established to guide the construction process. The stages and the subsequent objectives are as follows:

(1) Adaptation stage: To identify salient strategies, strategy groupings and scales from the literature;

(2) Initial development stage: To select relevant strategies, strategy groupings and scales for a draft questionnaire;

(3) Refinement stage: To refine the draft questionnaire format and content; and

(4) Validation stage: To pre-test and finalise the questionnaire. 
To ensure the objectives of each stage was achieved a number of processes were conducted and these are outlined in detail below.

\subsection{Stage 1: Adaptation}

The main purpose of this stage was to filter out the most prevalent strategies, classification schemes and scales for the draft ELLSQ. A comprehensive literature review was conducted in the field to identify the questionnaires that had been designed to assess LLSs among English learners. A summary of the most relevant questionnaires is presented in Table 1.

Table 1. Summary of typical questionnaires on LLSs

\begin{tabular}{|c|c|c|}
\hline Author (year) & Name & Description \\
\hline Oxford (1990) & $\begin{array}{l}\text { Strategy inventory for } \\
\text { language learning (SILL) }\end{array}$ & $\begin{array}{l}50 \text { items: } \\
\text { Direct strategies: Memory; Cognitive; } \\
\text { Compensation } \\
\text { Indirect strategies: Meta-cognitive; } \\
\text { Affective; Social }\end{array}$ \\
\hline Wen (1996) & $\begin{array}{l}\text { Learning beliefs and } \\
\text { learning strategies }\end{array}$ & $\begin{array}{l}43 \text { items: } \\
\text { Learning beliefs and Learning strategies } \\
\text { Management } \\
\text { Form-focused } \\
\text { Meaning-focused } \\
\text { Using-mother tongue beliefs }\end{array}$ \\
\hline Purpura (1999) & $\begin{array}{l}\text { Cognitive and } \\
\text { meta-cognitive strategy } \\
\text { use questionnaire }\end{array}$ & $\begin{array}{l}35 \text { items: } \\
\text { Cognitive strategies: Comprehending; } \\
\text { Retrieval } \\
\text { Meta-cognitive strategies: Planning; } \\
\text { Monitoring }\end{array}$ \\
\hline Cohen \& Chi (2002) & $\begin{array}{l}\text { Language Strategy Use } \\
\text { Inventory }\end{array}$ & $\begin{array}{l}90 \text { items: } \\
\text { Strategy Use groups: } \\
\text { Listening } \\
\text { Vocabulary } \\
\text { Speaking } \\
\text { Reading } \\
\text { Writing } \\
\text { Translation }\end{array}$ \\
\hline Griffiths (2003) & $\begin{array}{l}\text { English Language } \\
\text { Learning Strategy } \\
\text { Inventory }\end{array}$ & $\begin{array}{l}32 \text { items: } \\
\text { Not classified into groups }\end{array}$ \\
\hline
\end{tabular}


All questionnaires on LLSs have been based on one or more of the following schemes:

- contribution to/ involvement of the target language (i.e., direct or indirect);

- goal (i.e., for form-focused learning or for meaning focused use);

- intrinsic function (i.e., cognitive, meta-cognitive, memory, etc.);

- language modalities (i.e., productive or receptive skills); and

- learning setting (i.e., classroom related or classroom independent).

These classification schemes, which are applicable to a wide variety of language learning tasks (discrete or integrative), learning activities (micro or macro) and learning settings (formal or informal) were used to guide Stage 2 of initial development.

In terms of questionnaire scales, the frequency Likert scale (i.e., Never, Rarely, Sometimes, Often, Always/Almost always) or similar frequency scales were most predominantly used to assess LLSs. For this reason, the frequency Likert scale was chosen for the draft questionnaire.

Potentially relevant strategies from the questionnaires reviewed were then extracted, taking into account existing recommendations from the literature. The following inclusion and exclusion criteria were used for the selection process.

- A strategy statement should be explicitly aimed at a learning goal.

- A strategy statement should be measurable on the frequency scale.

- A strategy described could be observable (behaviours/actions) or unobservable (thoughts/mental processes).

- A strategy statement should not overlap with, include or be includerd by others.

- A strategy statement should not contain ambiguous words or meanings.

\subsection{Stage 2: Initial Development}

The initial development of the ELLSQ was carried out through consultation with survey experts and books, and focus group discussions with the target users and built upon information from Stage 1.

\subsubsection{Consultation with Survey Experts and Books}

Consultation with survey experts and literature was conducted to ensure that any latest developments surrounding the format, content, wording or structure of the questionnaire would be addressed appropriately. For this reason, this step contributed to establishing the salience and up-datedness of the questionnaire being developed.

A number of significant issues were taken into consideration as a result of the consultation. For example, an informative, short, and precise introduction was included to highlight the purpose of the survey and the benefits that respondents may gain from participation; special 
attention was given to the use of simple structure, appropriate format and the match between the stem (strategy statement) and the assessment scale (e.g., frequency scale in the ELLSQ); stereotyping, uncommon terminology, and leading words were avoided; and demographic questions were asked at the end to ensure that respondents would not be distracted.

\subsubsection{Discussion with Target Learners}

In addition to the top-down approach (the adaptation of existing questionnaires on LLSs in the literature and followed by consultation with experts), a bottom-up approach with target users was employed in the construction of the ELLSQ. These two integrative processes added value and dimension to the questionnaire.

In this bottom-up approach, focus group discussions were conducted with two small groups of 4-6 Vietnamese university students. Recruited through snowball sampling, these students were diverse in terms of gender, proficiency and major. The participants were asked to provide their comments on the list of strategies and schemes obtained from Stage 1. Their feedback was used as a reference point for the development of the ELLSQ draft version and resulted in the following modifications and additions.

- Certain strategies in the adapted list of strategies were alien to the students, such as the use of rhymes, flash cards or physical act-outs to remember new words. Explanations for the non-use of these strategies were elicited and some strategies were considered to be more suitable with younger and beginning learners of English (thus being contextually irrelevant) and some were not a common practice in the learning culture of the target learners (thus being culturally irrelevant). Because of their unpopularity or non-existence among the target users, these strategies were removed.

- The focus group participants also reported many frequently used strategies other than those covered in the adapted list. Their input led to the addition of a number of strategies, which were largely technology-based and culture-specific. Some typical examples are: I use online/computer-based materials; I join online forum(s) in English; I maintain a blog/Face-book/webpage in English; I use E-dictionaries or Pronunciation Software for model pronunciation of words/phrases; and I attend evening English classes.

- Some terminologies that confused participants were replaced, simplified, or clarified with examples; for instance: I read phonetic transcriptions of words in the dictionary (e.g., that/ðæt/); I use monolingual (English-English) dictionaries. In other cases, terms from the suggested categorisation schemes that caused confusion, such as cognitive or metacognitive, and direct or indirect were removed from the draft questionnaire.

Through the modification of unclear terms, removal of misfit strategy statements, and addition of more relevant ones, a draft version of the ELLSQ was devised. The classification schemes based on learning goals and language modalities/skills were also selected as recommended by participants. These two schemes were found to best reflect the current language teaching and learning curriculum, which is basically form-based (vocabulary, 
grammar, pronunciation) and skill-based (speaking, listening, writing and reading).

\subsubsection{Description of the ELLSQ First Draft}

The draft questionnaire was constructed with three main parts:

Part A - Your English learning strategy - consisted of 47 statements about language learning strategies measured on a frequency five-point Likert scale, including " $1=$ Never", " $2=$ Rarely", " $3=$ Sometimes", " $4=$ Often", and " $5=$ Always". With a view to making the questionnaire better structured, these 47 items were classified into three groups, including:

- Regulating strategies (strategies for regulating the learning process, such as manipulating diverse learning materials, creating learning opportunities and monitoring self-performance);

- Form-based strategies (strategies for learning the linguistic forms of the target language, including vocabulary, grammar and pronunciation); and

- Skill-based strategies (strategies for using the target language in meaning interpretation and meaning construction through four macro skills of reading, listening, speaking and writing).

Part B - Your beliefs and experience in English learning - contained 11 items on the English language beliefs and experience of the respondents which were considered closely related to their LLS choice and adoption. These 11 items covered self-perceived motivation, the role of self-discipline, the role of advanced technology, the role of grammar and vocabulary contextualisation, the role of culture, the role of practice and attitude towards mistakes in learning. Students' behaviours in relation to their reliance on teachers or peers were also examined. The questionnaire respondents were asked to indicate their level of agreement to 11 statements on a five-point rating scale, including " $1=$ Strongly Disagree", " $2=$ Disagree", "3=Not Sure", "4=Agree" and "5=Strongly Agree".

Part C - About you - included 5 items designed to collect participants' demographic information, such as gender, university year groups, academic majors, scores on international standardised tests, and self-rated English proficiency in the four macro skills of reading, speaking, listening and writing.

\subsection{Stage 3: Refinement}

After construction, the draft questionnaire was further refined through feedback from two experts in the field. As suggested by Bowling (2009) and Dillman (2000), it is highly recommended for experts to review and comment on a questionnaire. The aim of the review was to obtain an objective evaluation of the questionnaire's content, structure and format. With their consent, a review package was sent, including a summary of the rationale, intended purpose, and construction processes of the questionnaire; the conceptual framework, categorisation schemes and inclusion/exclusion criteria of the strategies; and the draft questionnaire.

The expert's general comments and suggestions were largely related to questionnaire 
formatting, wording of introduction and strategy items, and consistency in strategy statements. Concerning the frequency five-point Likert scale, it was suggested that "Always" be changed to "Always or almost always" to allow for approximation to "Always". There was also a suggestion on the renumbering of the questionnaire items.

In terms of wording, more consistency in expression of learning goals was requested (using To infinitive phrases), which underpinned the use of strategy groups. For example: "In terms of English learning resources" could be rephrased as "To access and integrate diverse learning resources". Based on their suggested revisions, "I go to English classes in the evening" was changed into "I attend evening English classes"; and "I learn by heart typical functional phrases in various situations" was replaced by "I memorise fixed phrases of different functions".

Lastly, specific comments were provided regarding how to make the introduction more concise and comprehensible to the target learners. The suggestions included the addition of open-ended items, where learners were encouraged to specify other strategies apart from those covered in the questionnaire. The open-ended questions allowed for the identification of any important strategies that may have been overlooked during the development stage.

Appropriate changes to the draft questionnaire were made based on the feedback provided, and a refined version for the questionnaire was developed.

\subsection{Stage 4: Validation}

The final step of the questionnaire construction involved the validation of its reliability and validity. A field pre-test was carried out with the participation of 97 students, who were part of the target population. The main purpose of this pilot test was to ensure the workability of the instrument or to establish whether the target users understood the questions, and to identify any other issues (Dillman, 2000).

A checklist for pre-testing was developed, containing questions about the administration, content and format of the questionnaire, such as questionnaire administration methods, actual completion time, the length of the questionnaire, readability of the print, comprehensibility of question items, and clarity of instruction. The participants were asked to fill in the questionnaire and invited to respond to the pre-testing checklist.

\subsubsection{Reliability}

The reliability of the ELLSQ items was assessed using Cronbach's Alpha coefficients, which are considered a standard measurement of reliability (Pallant, 2007). Cronbach's Alpha coefficients provide the researcher with information on the correlation between the questionnaire items and possible changes required. Cronbach's Alpha coefficient values above 0.7 are considered acceptable (Nunally \& Bernstein, 1994).

Of the 47 items in the ELLSQ, 13 items measure Regulating strategies, 14 items measure Form-based strategies and 20 items measure Skill-based strategies. The Cronbach's Alpha coefficient scores of the draft questionnaire suggested that the items formed reliable and highly reliable scales, as outlined in Table 2 . 
Table 2. Cronbach's Alpha scores of the ELLSQ items

\begin{tabular}{|l|c|c|}
\hline & Cronbach's Alpha & N of Items \\
\hline Regulating Strategies & .762 & 13 \\
\hline Form-based Strategies & .793 & 14 \\
\hline Skill-based Strategies & .900 & 20 \\
\hline
\end{tabular}

\subsubsection{Validity}

After conducting reliability analyses, the items in the questionnaire were checked for their face validity and tested against their construct validity using item analysis.

Face validity. Nearly half of the 97 participants provided specific comments related to the clarity of question wording, and the overall layout of the questionnaire. Positive comments were obtained regarding the instruction and question wordings, which reportedly did not cause confusion. It was felt that this was due to the questionnaire being developed with input from target users through focus groups. This bottom-up approach allowed for the filtering of ambiguous and confusing terms even prior to the pre-testing.

Regarding questionnaire administration, there was a preference for hard copy over electronic. The length of time for completing the questionnaire was 12 minutes on average. All participants completed the questionnaire in one sitting, and the majority agreed that it was readable and understandable.

In relation to the overall layout, the questionnaire was reported to be easy to navigate. However, through an examination of the responses to the open question (Question 48), it was noted that more space should be provided to accommodate respondents' feedback. In addition, when responding to question 63, Score(s) on international standardised English test(s), it was found that some students did not specify the test score in the given space, although they indicated having the test(s). For this reason, modification was made to include a clearer instruction in this question: "Please tick $(\sqrt{ })$ any international standardised English test $(s)$ that you have taken and specify your score(s) where applicable."

Construct validity. Item analysis was used to decide which items of the research instrument to be included or excluded from the scale (McAlpine, 2002). In principle, the item analysis procedure seeks to select a set of items which produce a summed score that is more strongly related to the construct of interest than any other possible set of items (Barnard, 1999; McAlpine, 2002).

The item analysis was conducted as follows:

Step 1: Calculating Corrected Item-Total Correlations for items in Scale 1 - Regulating Strategies (Appendix 1), the items in Scale 2 - Form-based Strategies (Appendix 2), the items in Scale 3 - Skill-based strategies (Appendix 3)

Step 2: Conducting Bivariate Correlations between: 
- Scale 1 (Regulating Strategies) items and the sum of Scale 2 (Form-based Strategies);

- Scale 1 (Regulating Strategies) items and the sum of Scale 3 (Skill-based Strategies) (Appendix 4).

Step 3: Repeat step 2 for Scale 2 (Form-based Strategies) items with the sum of Scale 1 (Regulating Strategies) and Scale 3 (Skill-based Strategies) (Appendix 5).

Step 4: Repeat step 2 for Scale 3 (Skill-based Strategies) items with the sum of Scale 1 (Regulating Strategies) and Scale 2 (Form-based Strategies) (Appendix 6).

Step 5: Performing item analysis on revised scales until a satisfactory set of items remains (Appendix 7).

As a whole, the item analysis was conducted on 47 question items which had been developed to assess Regulating, Form-based, and Skill-based Strategies. Each item was correlated with its own scale and then with other strategy scales. The Bivariate Correlations results indicated that 8 items were more correlated with another scale than their own scale, including items 1 , $14,17,18,19,23,31$, and 47 . However, item analysis is normally suggested to be used with discretion; that is, item selection in a scale should be based not only on the correlation scores, but also on how they rationally and theoretically relate to the constructs (McAlpine, 2002). As a result, a further examination of the content of the 8 items was undertaken. It was decided that item 17 (I guess meanings of words from contexts) in Scale 2 (Form-based Strategies) was more relevant to reading skills in Scale 3 (Skill-based Strategies). For this reason, item 17 was moved from Scale 2 to Scale 3. The remaining 7 items were rationally and thematically fitted with their own scales.

The construct validity of the revised scales was assessed again using Reliability Coefficients and Bivariate Correlations. The results in the below Appendix 7 indicated that 40 out of 47 items were more correlated with their own scale than with another scale, and the remaining 7 items were retained in their own scale either because of their higher thematic correlation with their own scale or the minimal differences in the bivariate correlation scores.

\section{The ELLSQ - Final Version}

The final version of the ELLSQ was constructed through after the four stage process as outlined previously and consisted of 47 closed-ended items and 1 open-ended item on English learning strategies; and 16 closed-ended items on learner variables, such as gender, university year groups, academic majors, self-rated English proficiency and beliefs about language learning. The 47 items on English learning strategies were classified into 3 main groups, namely (1) Regulating strategies; (2) Form-based Learning Strategies; and (3) Skill-based Strategies. These three groups were further divided into several sub-groups, which are summarised Figure 1. 


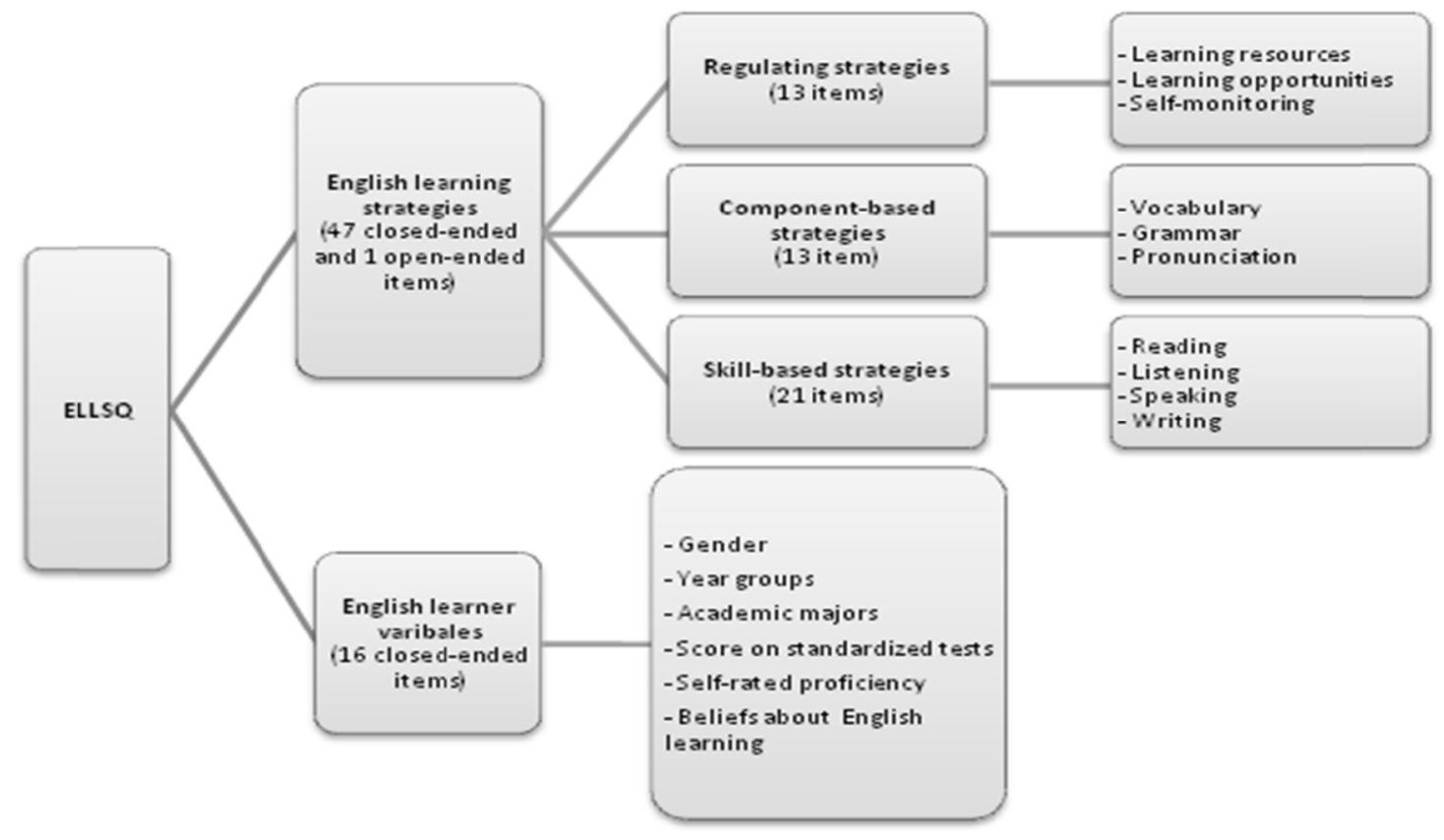

Figure 1. Final structure of the English Language Learning Strategy Questionnaire (ELLSQ)

\section{Conclusion}

This paper has provided a detailed explanation regarding the adaptation, initial development, refinement and validation of the English Language Learning Strategy Questionnaire (ELLSQ) among Vietnamese tertiary students. Through this comprehensive process of questionnaire construction and validation, it is suggested that the ELLSQ is reflective of and pertinent to the current contextual and cultural setting at tertiary learning level in Vietnam. With its well-presented reliability and validity, the ELLSQ could be used to examine the language learning strategies of learners in similar contexts on a large scale. It is recommended that the four-stage development process be replicated on the construction of other questionnaires as it plays an integral role in determining the rigor and trustworthiness of the study, especially through its use of a reliable and valid tool for collecting quantitative data.

As there has been little recent tool development that measures the range and patterns of LLS use by language learners, the development of a contextually and culturally relevant research tool as described within this paper is vital. It not only serves to be used within other language learning contexts among Vietnamese, but the strategies and processes used to develop and validate the questionnaire serves as a pattern to assist other teachers and researchers of language within various cultural contexts. This is particularly poignant within the age of technologically assisted language learning where new teaching and learning modes are constantly created, prompting learners to adopt new learning approaches and strategies. 


\section{Macrothink}

International Journal of English Language Education

ISSN 2325-0887

2016, Vol. 4, No. 1

\section{References}

Barnard, J. J. (1999). Item Analysis in Test Construction. In G. N. Masteres \& J. P. Keeves (Eds.), Advances in measurement in educational research and assessment (pp. 195-206): Pergamon.

Bialystok, E. (1978). A theoretical model of second language learning. Language Learning, 28(1), 69-83. http://dx.doi.org/10.1111/j.1467-1770.1978.tb00305.x

Bowling, A. (2009). Research methods in health: Investigating health and health services (3 ed.). Maidenhead, England: Open University Press.

Chamot, A. U. (2004). Issues in language learning strategy research and teaching. Electronic Journal of Foreign Language Teaching, 1(1), 14-26.

Cohen, A., \& Chi, J. (2002). Language strategy use inventory and index. Center for advanced research on language acquisition. Minneapolis, MN.

Cohen, A. D. (1998). Strategies in learning and using a second language. London: Longman.

Dillman, D. (2000). Constructing the questionnaire. Mail and internet surveys. New York: John Wiley \& Sons.

Gan, Z. (2004 ). Attitudes and strategies as predictors of self-directed language learning in an EFL context. International Journal of Applied Linguistics, 14(3), 389-411. http://dx.doi.org/10.1111/j.1473-4192.2004.00071.x

Grenfell, M., \& Erler, L. (2007). Language learner strategies. Language Learning Journal, 35(1), 5-7. http://dx.doi.org/10.1080/09571730701315535

Griffiths, C. (2003). Language learning strategy use and proficiency: The relationship between patterns of reported language learning startegy (LLS) use by speakers of other languages (SOL) and proficiency with implications for the teaching/learning situation Thesis submitted in fulfilment of the requirements for the degree Doctor of Philosophy.

MacIntyre, P. (1994). Toward a social psychological model of strategy use. Foreign Language Annuals, 27(2), 185-195. http://dx.doi.org/10.1111/j.1944-9720.1994.tb01201.x

Magno, C. (2010). Korean students' language learning strategies and years of studying English as predictors of proficiency in English. TESOL Journal, 2, 39-61.

McAlpine, M. (2002). A summary of methods of item analysis: CAA Centre, University of Luton.

Nunally, J. C., \& Bernstein, I. H. (1994). Psychometric theory (3rd ed.). New York, NY: McGraw-Hill.

Oxford, R. L. (1986). Development and psychometric testing of the Strategy Inventory for Language Learning (SILL). Alexandria, VA: Army Research Institute.

Oxford, R. L. (1990). Language learning strategies : what every teacher should know. New 
York: Newbury House Publisher.

Oxford, R. L., \& Ehrman, M. E. (1995). Adults' language learning strategies in an intensive foreign language program in the United States. System, 23, 359-386. http://dx.doi.org/10.1016/0346-251X(95)00023-D

Pallant, J. (2007). SPSS: A step by step guide to data analysis using SPSS for windows (Version 15) (3rd ed.). Crows Nest, NSW: Allen \& Unwin.

Prakongchati, N. (2007). Factors related to the use of language learning strategies by Thai public university freshmen. (doctoral dissertation), Suranaree University of Technology, Thailand.

Purpura, J. (1999). Learner strategies use and performance on language tests: A structural modelling approach. Cambridge, England: Cambridge University Press.

Rubin, J., \& Wenden, A. (1987). Learner strategies in language learning. Englewood Cliffs ; London: Prentice-Hall International.

Su, M.-H., \& Duo, P.-C. (2012). EFL Learners' Language Learning Strategy use and Perceived Self-Efficacy. European Journal of Social Sciences, 27(3), 335-345.

Usuki, M. (2000). A new understanding of Japanese students views on classroom learning. Independence, 27, 2-6.

Wen, Q. (1995). Differences in strategy use between successful and unsuccessful learners. Foreign Language Teaching and Research, 3, 61-66.

Wen, Q. (1996). On English Learning Strategies. Shanghai: Shanghai Foreign Language Education Press.

Yin, C. (2008). Language learning strategies in relation to attitudes, motivations and learner beliefs: Investigating learner variables in the context of English as a foreign language in China. Unpublished doctoral dissertation. University of Maryland, College Park.

Zare, P. (2010). An investigation into language learning strategy use and gender among Iranian undergraduate language learners. World Applied Sciences Journal, 11(10).

\section{Appendices}

Appendix 1. Corrected Item-Total Correlations for items in Scale 1-Regulating Strategies

\begin{tabular}{|l|l|}
\hline \multicolumn{1}{|c|}{ Scale 1: Regulating strategies } & Item-Total Correlations \\
\hline 1. I use academic print materials & .108 \\
\hline 2. I use non-academic print materials & .406 \\
\hline 3. I use traditional broadcast materials & .375 \\
\hline 4. I use recorded materials (audio/video tapes, CDs). & .358 \\
\hline 5. I use online/computer-based materials & .371 \\
\hline
\end{tabular}




\begin{tabular}{|l|l|}
\hline 6. I use monolingual (English-English) dictionaries. & .314 \\
\hline 7. I attend events where English is used & .446 \\
\hline 8. I attend evening English classes. & .291 \\
\hline 9. I communicate with foreigners & .499 \\
\hline 10. I join online forum(s) in English. & .347 \\
\hline 11. I maintain a blog/Face-book/webpage in English. & .389 \\
\hline 12. I set specific goals for improving my English. & .523 \\
\hline 13. I monitor my progress in English. & .579 \\
\hline
\end{tabular}

Appendix 2. Corrected Item-Total Correlations for items in Scale 2-Form-based Strategies

\begin{tabular}{|l|l|}
\hline \multicolumn{1}{|c|}{ Scale 2: Form-based strategies } & Item-Total Correlations \\
\hline 14. I record words in groups or phrases & .417 \\
\hline 15. I rewrite words many times to remember their spellings. & .195 \\
\hline 16. I break new words into parts that I know. & .366 \\
\hline 17. I guess meanings of words from contexts. & .429 \\
\hline 18. I make sentences that contain new words. & .479 \\
\hline 19. I learn words by topics. & .245 \\
\hline 20. I memorise grammar rules and structures. & .533 \\
\hline 21. I do grammar exercises. & .394 \\
\hline 22. I make my own sentences using new structures. & .490 \\
\hline 23. I analyse the grammatical structures of different texts. & .388 \\
\hline $\begin{array}{l}\text { 24. I read phonetic transcriptions of words in the dictionary (e.g., } \\
\text { that / dæt/). }\end{array}$ & .352 \\
\hline $\begin{array}{l}\text { 25. I use Electronic dictionaries or Pronunciation Software for model } \\
\text { pronunciation of words/phrases. }\end{array}$ & .429 \\
\hline 26. I practice unfamiliar sounds by saying them again and again. & .509 \\
\hline 27. I repeat after native speakers & .505 \\
\hline
\end{tabular}

Appendix 3. Corrected Item-Total Correlations for items in Scale 3-Skill-based Strategies

\begin{tabular}{|l|l|}
\hline \multicolumn{1}{|c|}{ Scale 3: Skill-based strategies } & Item-Total Correlations \\
\hline $\begin{array}{l}\text { 28. I read over the text quickly for main ideas before reading } \\
\text { carefully. }\end{array}$ & .581 \\
\hline 29. I identify the organisation of the text & .512 \\
\hline 30. I skip unimportant words & .536 \\
\hline 31. I make predictions about what will come next. & .441 \\
\hline 32. I make summaries about the text & .568 \\
\hline 33. I reread part of the text to understand better. & .621 \\
\hline 34. I pay attention to non-verbal cues & .481 \\
\hline 35. I listen for key words or ideas. & .566 \\
\hline
\end{tabular}


36. I take notes of key words or ideas 627

37. I ask the speaker to clarify/repeat to understand better in a .502 conversation.

38. I memorise what to say in various situations .586

39. I practice speaking to myself. .517

40. I explain or give examples if I don't know the exact words.

.621

41. I use synonyms or simpler words if I don't know the exact words. $\quad .510$

42. I use body language to help express what I want to say.

392

43. I look for formal ways to express ideas

.636

44. I make an outline of main points before writing.

.491

45. I draft my writing. .568

46. I revise my writing to improve the language and content.

.536

47. I ask others to comment on my writing.

Appendix 4. Bivariate Correlations between items in Scale 1 and the sum of Scales 2, 3

\begin{tabular}{|l|l|l|l|}
\hline \multicolumn{1}{|c|}{ Scale 1: Regulating strategies } & Scale & Scale 2 & Scale 3 \\
\hline 1. I use academic print materials & .108 & .178 & .313 \\
\hline 2. I use non-academic print materials & .406 & .324 & .192 \\
\hline 3. I use traditional broadcast. & .375 & .135 & .194 \\
\hline 4. I use recorded materials & .358 & .296 & .265 \\
\hline 5. I use online/computer-based materials & .371 & .246 & .304 \\
\hline 6. I use monolingual (English-English) dictionaries. & .314 & .262 & .285 \\
\hline 7. I attend events where English is used & .446 & .172 & .231 \\
\hline 8. I attend evening English classes. & .291 & .216 & .155 \\
\hline 9. I communicate with foreigners & .499 & .322 & .357 \\
\hline 10. I join online forum(s) in English. & .347 & .288 & .292 \\
\hline 11. I maintain a blog/Face-book/webpage in English. & .389 & .362 & .312 \\
\hline 12. I set specific goals for improving my English. & .523 & .454 & .481 \\
\hline 13. I monitor my progress in English. & .579 & .558 & .515 \\
\hline
\end{tabular}

Appendix 5. Bivariate Correlations between items in Scale 2 and the sum of Scales 1, 3

\begin{tabular}{|l|l|l|l|}
\hline \multicolumn{1}{|c|}{ Scale 2: Form-based strategies } & Scale 1 & Scale 2 & Scale 3 \\
\hline 14. I record words in groups or phrases & .423 & .417 & .374 \\
\hline 15. I rewrite words many times to remember their spellings. & .046 & .195 & .106 \\
\hline 16. I break new words into parts that I know. & .268 & .366 & .249 \\
\hline 17. I guess meanings of words from contexts. & .464 & .429 & .488 \\
\hline 18. I make sentences that contain new words. & .439 & .479 & .512 \\
\hline 19. I learn words by topics. & .436 & .245 & .372 \\
\hline 20. I memorise grammar rules and structures. & .217 & .533 & .352 \\
\hline 21. I do grammar exercises. & .180 & .394 & .314 \\
\hline
\end{tabular}




\begin{tabular}{|l|l|l|l|}
\hline 22. I make my own sentences using new structures. & .316 & .490 & .383 \\
\hline 23. I analyse the grammatical structures of different texts. & .251 & .388 & .410 \\
\hline 24. I read phonetic transcriptions of words in the dictionary & .283 & .352 & .273 \\
\hline $\begin{array}{l}\text { 25. I use Electronic dictionaries or Pronunciation Software for } \\
\text { model pronunciation of words/phrases }\end{array}$ & .331 & .429 & .411 \\
\hline $\begin{array}{l}\text { 26. I practice unfamiliar sounds by saying them again and } \\
\text { again. }\end{array}$ & .227 & .509 & .461 \\
\hline 27. I repeat after native speakers & .288 & .505 & .483 \\
\hline
\end{tabular}

Appendix 6. Bivariate Correlations between items in Scale 3 and the sum of Scales 1, 2

\begin{tabular}{|l|l|l|l|}
\hline \multicolumn{1}{|c|}{ Scale 3: Skill-based strategies } & Scale 1 & Scale 2 & Scale 3 \\
\hline $\begin{array}{l}\text { 28. I read over the text quickly for main ideas before reading } \\
\text { carefully. }\end{array}$ & .329 & .459 & .581 \\
\hline 29. I identify the organisation of the text & .400 & .438 & .512 \\
\hline 30. I skip unimportant words & .352 & .458 & .536 \\
\hline 31. I make predictions about what will come next. & .477 & .352 & .441 \\
\hline 32. I make summaries about the text & .433 & .425 & .568 \\
\hline 33. I reread part of the text to understand better. & .246 & .447 & .621 \\
\hline 34. I pay attention to non-verbal cues & .445 & .391 & .481 \\
\hline 35. I listen for key words or ideas. & .304 & .370 & .566 \\
\hline 36. I take notes of key words or ideas & .342 & .442 & .627 \\
\hline $\begin{array}{l}\text { 37. I ask the speaker to clarify/repeat to understand better in a } \\
\text { conversation. }\end{array}$ & .256 & .390 & .502 \\
\hline 38. I memorise what to say in various situations & .384 & .454 & .586 \\
\hline 39. I practise speaking to myself. & .351 & .486 & .517 \\
\hline $\begin{array}{l}\text { 40. I explain or give examples if I don't know the exact } \\
\text { words. }\end{array}$ & .426 & .544 & .621 \\
\hline $\begin{array}{l}\text { 41. I use synonyms or simpler words if I don't know the exact } \\
\text { words. }\end{array}$ & .350 & .382 & .510 \\
\hline 42. I use body language to help express what I want to say. & .321 & .291 & .392 \\
\hline 43. I look for formal ways to express ideas & .372 & .444 & .636 \\
\hline 44. I make an outline of main points before writing. & .307 & .353 & .491 \\
\hline 45. I draft my writing. & .199 & .363 & .568 \\
\hline 46. I revise my writing to improve the language and content. & .216 & .391 & .536 \\
\hline 47. I ask others to comment on my writing. & .263 & .321 & .279 \\
\hline
\end{tabular}

Appendix 7. Bivariate Correlations between items in the revised Scales 1, 2 and 3

\begin{tabular}{|l|l|l|l|}
\hline \multicolumn{1}{|c|}{ Scale 1: Regulating strategies } & \multicolumn{1}{c|}{ Scale 1 } & Scale 2 & Scale 3 \\
\hline 1. I use academic print materials & .108 & .158 & .315 \\
\hline 2. I use non-academic print materials & .406 & .305 & .213 \\
\hline 3. I use traditional broadcast materials & .375 & .130 & .194 \\
\hline
\end{tabular}




\begin{tabular}{|c|c|c|c|}
\hline 4. I use recorded materials & .358 & .276 & .274 \\
\hline 5. I use online/computer-based materials & .371 & .238 & .318 \\
\hline 6. I use monolingual (English-English) dictionaries. & .314 & .258 & .292 \\
\hline 7. I attend events where English is used & .446 & .172 & .222 \\
\hline 8. I attend evening English classes. & .291 & .205 & .165 \\
\hline 9. I communicate with foreigners & .499 & .315 & .358 \\
\hline 10. I join online forum(s) in English. & .347 & .287 & .290 \\
\hline 11. I maintain a blog/Face-book/webpage in English. & .389 & .348 & .322 \\
\hline 12. I set specific goals for improving my English. & .523 & .412 & .496 \\
\hline 13. I monitor my progress in English. & .579 & .551 & .519 \\
\hline Scale 2: Form-based strategies & Scale 1 & Scale 2 & Scale 3 \\
\hline 14. I record words in groups or phrases & .413 & .406 & .365 \\
\hline 15. I rewrite words many times to remember their spellings & .046 & .198 & .114 \\
\hline 16. I break new words into parts that I know & .268 & .352 & .260 \\
\hline 17. I make sentences that contain new words & .439 & .461 & .522 \\
\hline 18. I learn words by topics & .436 & .260 & .357 \\
\hline 19. I memorise grammar rules and structures & .217 & .521 & .366 \\
\hline 20. I do grammar exercises & .180 & .408 & .307 \\
\hline 21. I make my own sentences using new structures & .316 & .495 & .385 \\
\hline 22. I analyse the grammatical structures of different texts & .251 & .389 & .410 \\
\hline 23. I read phonetic transcriptions of words in the dictionary & .283 & .347 & .279 \\
\hline $\begin{array}{l}\text { 24. I use Electronic dictionaries or Pronunciation Software } \\
\text { for model pronunciation of words/phrases. }\end{array}$ & .331 & .443 & .408 \\
\hline $\begin{array}{l}\text { 25. I practice unfamiliar sounds by saying them again and } \\
\text { again. }\end{array}$ & .227 & .484 & .479 \\
\hline 26. I repeat after native speakers & .288 & .481 & .487 \\
\hline Scale 3: Skill-based strategies & Scale 1 & Scale 2 & Scale 3 \\
\hline $\begin{array}{l}\text { 27. I read over the text quickly for main ideas before } \\
\text { reading carefully. }\end{array}$ & .329 & .436 & .593 \\
\hline 28. I identify the organisation of the text & .400 & .427 & .522 \\
\hline 29. I skip unimportant words & .352 & .460 & .535 \\
\hline 30. I guess meanings of words from contexts. & .478 & .375 & .492 \\
\hline 31. I make predictions about what will come next. & .477 & .336 & .450 \\
\hline 32. I make summaries about the text & .433 & .417 & .570 \\
\hline 33. I reread part of the text to understand better. & .246 & .444 & .613 \\
\hline 34. I pay attention to non-verbal cues & .445 & .392 & .485 \\
\hline 35. I listen for key words or ideas. & .304 & .367 & .562 \\
\hline 36. I take notes of key words or ideas & .342 & .453 & .612 \\
\hline $\begin{array}{l}\text { 37. I ask the speaker to clarify/repeat to understand better in } \\
\text { a conversation. }\end{array}$ & .256 & .389 & .498 \\
\hline 38. I memorise what to say in various situations & .384 & .422 & .590 \\
\hline 39. I practise speaking to myself. & .351 & .479 & .519 \\
\hline
\end{tabular}




\begin{tabular}{|l|l|l|l|}
\hline $\begin{array}{l}\text { 40. I explain or give examples if I don't know the exact } \\
\text { words. }\end{array}$ & .426 & .526 & .630 \\
\hline $\begin{array}{l}\text { 41. I use synonyms or simpler words if I don't know the } \\
\text { exact words. }\end{array}$ & .350 & .359 & .516 \\
\hline 42. I use body language to help express what I want to say. & .321 & .283 & .393 \\
\hline 43. I look for formal ways to express ideas & .372 & .431 & .642 \\
\hline 44. I make an outline of main points before writing. & .307 & .343 & .494 \\
\hline 45. I draft my writing. & .199 & .352 & .569 \\
\hline 46. I revise my writing to improve the language and content. & .216 & .386 & .536 \\
\hline 47. I ask others to comment on my writing. & .263 & .341 & .267 \\
\hline
\end{tabular}

\section{Copyright Disclaimer}

Copyright for this article is retained by the author(s), with first publication rights granted to the journal.

This is an open-access article distributed under the terms and conditions of the Creative Commons Attribution license (http://creativecommons.org/licenses/by/3.0/). 